\title{
Can Monetary Incentive Regulate Boarding Passenger Distribution on the Metro Station Platform?
}

\author{
Jiajie Yu, ${ }^{1}$ Chenchen Kuai, ${ }^{1}$ Yanjie Ji $\mathbb{D},{ }^{1,2,3}$ and Liangpeng Gao $\mathbb{D}^{4}$ \\ ${ }^{1}$ School of Transportation, Southeast University, Nanjing 211189, China \\ ${ }^{2}$ Jiangsu Key Laboratory of Urban ITS, Jiangsu Province Collaborative Innovation Center of Modern Urban Traffic Technologies, \\ Nanjing 211189, China \\ ${ }^{3}$ National Demonstration Center for Experimental Road and Traffic Engineering Education, Nanjing 211189, China \\ ${ }^{4}$ School of Transportation, Fujian University of Technology, Fuzhou 350118, China \\ Correspondence should be addressed to Yanjie Ji; jiyanjie@seu.edu.cn
}

Received 30 April 2021; Revised 8 August 2021; Accepted 21 August 2021; Published 9 September 2021

Academic Editor: Ren-Yong Guo

Copyright (C) 2021 Jiajie Yu et al. This is an open access article distributed under the Creative Commons Attribution License, which permits unrestricted use, distribution, and reproduction in any medium, provided the original work is properly cited.

\begin{abstract}
To equilibrate the passenger distribution on the metro platform and carriage, a monetary incentive policy was explored in this paper; a discount on travel fare was provided to motivate metro passengers to queue for boarding in the noncrowded areas on the platform. The congested state is evaluated combined with the passenger distribution in the upcoming metro carriage. The utility of metro passengers and companies caused by the monetary incentive policy was analyzed, and the binary logit model was used to relate the utility to the passenger's willingness to move from crowded areas to noncrowded ones. With data acquired from the questionnaire survey, a regression analysis was employed to explain the variation in passengers' willingness to move as a function of discount level as well as personal and trip characteristics. The regression results show that effect of incentive discount is greater on female passengers and elderly passengers. A $10 \%$ discount can motivate most passengers aged over 40 , and a $30 \%$ discount works on most female passengers. According to the different levels of passenger sensitivity, a particular discount can be determined to motivate a specific proportion of passengers to move and achieve the regulation of passenger distribution on the metro station platform and metro carriage.
\end{abstract}

\section{Introduction}

In the wake of the rapid increase in urban population, the congestion problem occurs not only on roads but also in public transportation stations with large passenger flow. As the road traffic condition is getting worse, more travellers choose to commute by metro and the demand increases rapidly, especially during peak hours. Meanwhile, metro station platforms are usually long and narrow with 20-40 gates for passengers queuing to board. For example, there are 30 gates in each metro station of Nanjing metro line 3, and passengers form 60 queues (two queues around each gate) to board. Though there are instructions on the wall and workers around the gates to guide passengers and tell them which gates are more uncrowded, the passenger distribution is still disequilibrium, which causes the congested state unbalanced in metro carriage. Through video recording and field investigation in Nanjing South Railway Station during 17:30-18:30 (peak hour), Friday, June 25, 2021, it revealed that most of the passengers were gathered around stairways, as shown in Figure 1. Nanjing South Railway Station is a transfer station of Metro Line 3 and Line 1. There are 30 gates for passengers boarding and alighting in this metro station platform. The numbers in Figure 1 represent the identify number of boarding gates, and the blue circles represent metro passengers. The gate numbers around stairs are 6,16 , and 25. Two of them are with the longest queue length of boarding passengers. According to field studies, the distribution of passengers is disequilibrated even in peak hours. The disequilibrium of queue length in the metro station affects the distribution of passengers in metro carriage, thus leading to potential safety hazards and the 


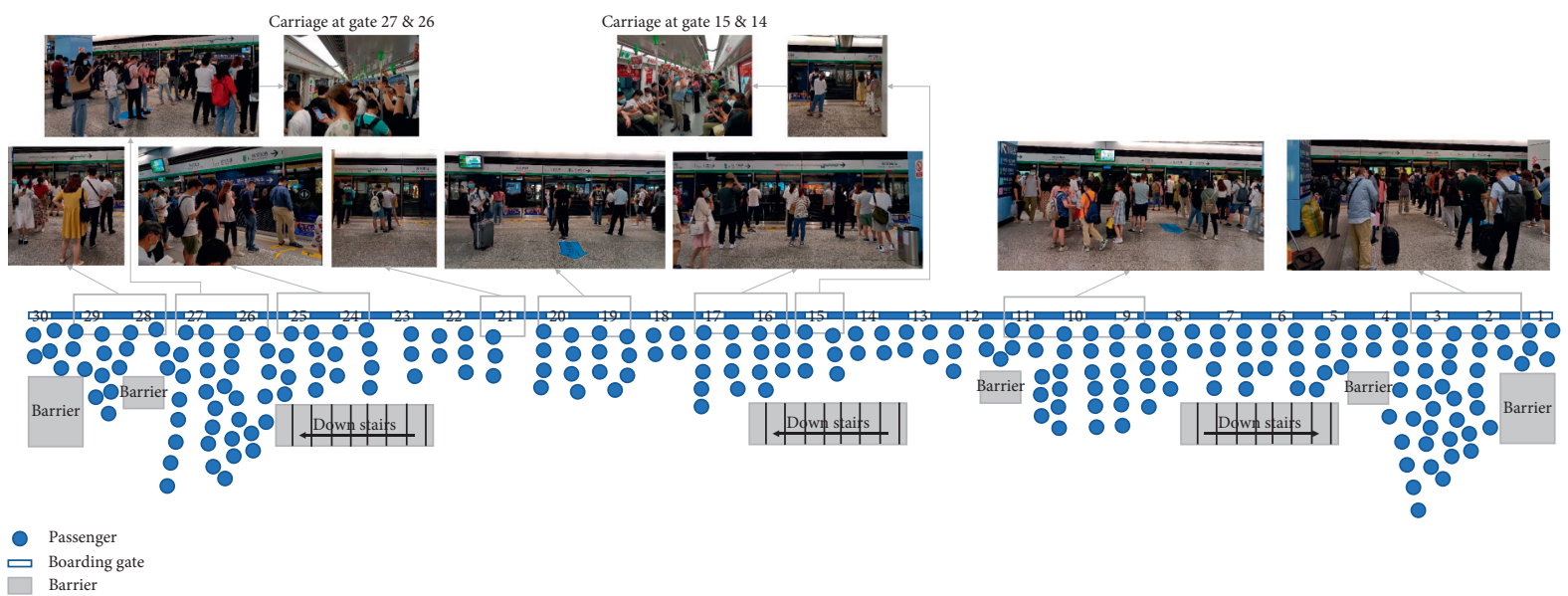

FIgURE 1: Distribution of passengers on the metro station platform.

reduction of service rate of the whole metro system $[1,2]$. Thus, a more equilibrated and uncrowded boarding environment for metro passengers is needed.

There exist some studies which reveal the passenger distribution rules in the metro platform. Krstanoski [3] found that there are several types of metro passengers, e.g., regular transit users prefer to choose the position of the platform exit to board, and some passengers prefer the uncrowded position to gain more comfort. As a result of all of these factors, the passenger distribution is highly relevant to the position of station exits and entrances. High percentage passengers are concentrated around the exits/entrance position to board, and the distribution pattern shows stability over the time in their survey. These findings were also reported by Wirasinghe and Szplett [4].

Except the distribution rules of boarding passengers, Krstanoski [3] also explored the distribution of alighting passengers. Passengers in the metro carriage are less likely to move between two adjacent carriages because the high loads in carriage makes passengers' movements difficult or practically impossible. Thus, "the distribution of alighting passengers will depend on which car passengers have boarded. This means that the same factors that influence the boarding passengers' distribution will influence the distribution of alighting passengers [3].”

Most of the studies on queueing disequilibrium phenomena are focused on vehicles and requests for network servers. The common method applied to equilibrate the queue length of vehicles is adjusting the control scheme for intersection signals [5-9]. Jang et al. [10] proposed a signal optimization algorithm to equalize the growth rate of queues between links in an oversaturated urban road network in order to relieve queue overflow formed in local areas of the network. Through the simulation experiments and comparison with the benchmark algorithm, the proposed queue growth equalization algorithm provides better performance on outflows, delays, and vehicle miles travelled [10]. As for network servers, Boon et al. [1] explored balance equations for multidimensional queue-length processes for a quite general network of multiclass multiserver queues. They found that an asymptotic relationship may obtain queueing characteristics with some error bounds, not assuming any stationarity condition. They also extended the distributional relationships for a nonstationary framework [1]. The equalization of queuing length can enlarge the queuing system capacity, maximize the utilization of infrastructure, and even shorten the waiting time in a queuing system $[1,10-12]$. Various models and theories were developed to conduct the analysis. The queuing theory is used widely and can be applied not only on transportation but other research fields, such as telecommunication and management science [13-16]. Queuing theory is used to provide a waiting list at queue when the arrival rate is higher than service rate in a system, which makes the system have enough rooms to store all request [13]. Liu et al. [17] proposed a cooperative hypercube queueing model to describe the situation where emergency vehicles perform cooperative services. The simulation results showed that the proposed model can illustrate cooperative performance effectively [17]. The load balancing strategic model and queueing network model are also useful tools to analyze the system performance from an abstract model [18, 19]. Osorio et al. [20] proposed an analytic queueing network model based on a decomposition of network into single queues. This model was applied to the patient flow in a hospital and showed better performance than existing approaches [20]. Wang et al. [21] presented a double-ended queueing system for passenger-taxi service. They studied the equilibrium strategies and socially optimal strategies by a reward-cost structure and proved the effect of the proposed system under different information levels [21]. However, these models mentioned above are not suitable to apply to the queue system on a metro station platform because there is no clear dividing line for each boarding queue. Passengers' behaviour is not controlled by the system, and they are allowed to change their position and queue line optionally.

Travellers' behaviour is led by their utility. A traveller will choose the action with the largest benefit for himself/herself [22]. Thus, the motivating approaches according to adjusting the utility of passengers can be considered to equilibrate passenger distribution. The study of queueing systems under a game-theoretic perspective was initiated by Naor [23]. He 
considered a fully observable queueing system with one server where customers choose whether to balk or to join based on the service rewards and the waiting time [23]. Then, the strategic behaviour of customers that arrive at a certain transportation station or a queueing system and face the joining or balking dilemma became a focus of the research regarding queuing [24-26]. Many scholars studied that how customers would make their join/balk decisions under different information scenarios and tried to analyze their behaviours by Nash equilibrium strategies or some other models [10, 27-29]. Manou et al. [26] considered the problem of studying customer strategic behaviour in a transportation station, where customers arrive according to a Poisson process and gave out the symmetric Nash equilibrium strategies for customers [26]. Liu et al. [30] modelled a queue system with service quality feedback and system maintenance. Through numerical examples, the effect of equilibrium and optimal balking strategies were provided [30].

If customers in a service system all act to maximize the welfare of themselves, the final state of the system is the user equilibrium. It is varied from the equilibrium from the social perspective [11]. To make up for this deficiency, it is found that congestion pricing can change the user equilibrium state to the system optimal one [31, 32]. Thus, the policy of monetary incentive became popular in the field of transportation. The idea which increases the efficiency of road usage by pricing was proposed in the 1920s and gained popularity among economists [33-35]. Vehicles that pass pricing roads are charged an extra fare so that some of travellers will choose other routes to complete their travel. In recent decades, congestion pricing was being widely applied to many cities such as Durham (2002), London (2003), Stockholm (2006), and Milano (2008) to reduce traffic congestion [36-39]. Congestion pricing has become an effective way to reallocate and equalize the users' demand [40-42].

Based on the analysis above, it can be assumed that if a discount on travel fare is applied to metro passengers, it might motivate more passengers to move towards noncrowded areas or specified positions on the platform, to achieve the equilibrium of passenger distribution in the metro system. This paper presents the analyses of the utility of metro passengers and companies being applied to the monetary incentive policy. The function between passengers' willingness to move and the level of discount was established by the binary logit model. Using the data collected from the questionnaire survey, the passengers' preferences were analyzed using regression analysis, and the specific operation process of the monetary incentive policy for metro passengers was proposed.

\section{Method}

2.1. Concept of the Monetary Incentive Policy for Metro Passengers. In the congestion pricing policy, a fee is charged to all vehicles accessing a specific road/area during the specified period. Some travellers would choose to travel at other times or use other roads to complete the journey $[43,44]$. Congestion pricing is a form of negative monetary incentives, which motivate some travellers to change their decisions to avoid the payment.

However, for metro passengers, extra fees may lead to a decrease in patronage, which is inconsistent with the lowcarbon concept of urban development. Therefore, this paper discusses the impact of negative congestion pricing, i.e., using the discount on travel fee to encourage passengers to move from crowded areas to noncrowded areas or specified positions for boarding on the metro station platform. The hypothesis is that the negative congestion pricing, as a form of positive monetary incentives, would motivate passengers to move.

The technical preconditions needed to support the implementation of the monetary incentive policy for metro passengers are as follows:

(i) Crowded areas and noncrowded areas on the platform are distinguished by a video identification system, such as YOLO [45]. This kind of system or technology can detect objects such as persons and vehicles automatically in real time. Combined with the congested state in the metro carriage, the specified positions where passengers are supposed to board can be distinguished, and how many passengers should be moving from crowded areas to noncrowded areas and specified positions can be calculated. The two types of areas are always consistent according to our survey and studies in Krstanoski [3].

According to Larsson et al. [2], "the recommended maximum crowd density for standing spectators and people queuing is $4.0 \mathrm{pers} / \mathrm{m}^{2}$." So, when the crowd density is larger than 4.0 pers $/ \mathrm{m}^{2}$, this area can be distinguished as a crowded area. Otherwise, it is noncrowded areas. The number of passengers recommended to move to noncrowded areas is the difference between real density and 4.0 pers $/ \mathrm{m}^{2}$.

The congested state in metro carriages is easy to obtain, which has already achieved and was exhibited by the screen in metro carriages in many cities (e.g., Changsha city, China).

(ii) Relevant information should be displayed on the platform's information board, including gate number of the specified area and the discount level they will get if they move to noncrowded areas.

(iii) Card readers (a kind of machine used to read information on a card by RFID or NFC) are arranged on the walls in the metro station. Passengers queuing in specified areas can record their smart card numbers by swiping their cards while they are waiting for trains, and card readers in crowded areas do not work, thus identifying the benefitted group.

The implementation steps of monetary incentive for metro passengers are shown as below.

(i) Step 1. Through a simple calculation of the information collected from the monitoring system and metro carriages, the metro company can determine 
the optimal proportion of passengers to move and the discount that passengers can acquire. The information of gate number and discount will be shown on the information board.

(ii) Step 2. Upon seeing the real-time information of gate numbers and discounts, passengers in crowded areas decide whether to move.

(iii) Step 3. If passengers decide to move, they need to swipe their cards at the card reader in the noncrowded/specified area to receive the discount. No action is required for passengers deciding not to move.

After these steps, card numbers of passengers in noncrowded/specified areas have been recorded and the travel fare will be reduced according to the discount when they get out of the metro station.

Nevertheless, there will be some troubling situations in the implementation process of the above schemes, which will be elaborated as follows:

(i) How to prevent a passenger who has claimed the incentive to move back to their original waiting area?

When the passengers have claimed the incentive, this means they have swiped their IC cards in noncrowded areas. It is illogical for passengers in the noncrowded area moving again to crowded areas without any awards because they will pay out physical energy consumption and reduce the comfort level if they do so. So, this situation is almost impossible.

(ii) Is it possible that the incentive policy may attract passengers to a particular area such that the noncrowded area becomes overcrowded instead?

If the discount is large enough that can motivate all types of passengers to move, of course the noncrowded areas will become overcrowded. However, the lower level of discount may motivate specific categories of passengers to move due to the different sensitivity to discount of each passenger. So, if the discount level is set scientifically, the percentage of passengers who are motivated can be controlled according to demand.

The purpose of this work is to find an appropriate discount level that can motivate a particular proportion of passengers to move. The selected discount level will not be so high that too many passengers are motivated and move to the noncrowded area to make it crowded. Combined with the real-time information collection and display, such a situation will be avoided as much as possible. If this case still occurs, the solution is stopping the discount or renewing the crowded and discount information until the distribution of passengers gets equilibrium.

(iii) Some passengers do not swipe their cards in the noncrowded area after moving.
This will not affect the operation of the system, but the benefit distribution between the passengers and the metro company will be varied. The impact will be defined and discussed later in this paper.

2.2. Utility Analysis. The utility of metro passengers and the company will be analyzed from a game-theoretic perspective. The form of bonus studied in this paper is a discount on the one-way-ticket fare. Passengers are encouraged to move from crowded areas to noncrowded/specified areas on the platform by receiving a discount on their travel fare.

2.2.1. Utility of Metro Passengers. Passengers may be positioned anywhere on the platform and moving from the crowded area to the noncrowded/specified area will consume their physical energy. The average physical energy consumption from any position to the noncrowded/specified area is defined as $F$. The physical energy consumption is relative to walking distance. However, the exact location of passengers on the platform cannot be recognized at present, so we choose the average physical energy consumption to represent this cost in general. The discount on the travel fare offered by the metro company is $x$, and the payoff function of passengers who choose to move is as follows:

$$
W(x)=\mu x C-F,
$$

where $C$ is the original fare for the trip and $\mu$ is the passenger's psychological perception coefficient of discount, which means the passenger's perceived value of the discount may be lower or higher than the market value of the actual discount amount.

Passengers' choice is represented by $\lambda$. If $\lambda=1$, the passenger chooses to move; if $\lambda=0$, he/she chooses to stay. The probability of moved passengers to swipe their card at a card reader is set as $\theta$. If passengers choose not to move, their comfort level is reduced by staying in the crowded areas. The average comfort level reduction of passengers in crowded areas is expressed by $d$.

2.2.2. Utility of Metro Company. If passengers choose to move, the payoff of the metro company is as much as the discount delivered. If passengers choose not to move, the distribution of passengers and the use of resources in the platform is not an equilibrium. Compared to the saturation state, there is a reduction in capacity, leading the loss of benefit which is represented by $\rho$.

The variables and parameters involved in the utility analysis of metro passengers and the company are summarized in Table 1. All the variables and parameters are measured by economic value.

2.2.3. Payoff Function. The payoffs of the metro passenger and company under different strategies are shown in Table 2.

According to the analysis above, the payoff functions of the metro passenger and company can be obtained as follows: 
TABLE 1: Variables in the utility analysis.

\begin{tabular}{|c|c|}
\hline Variables & Explanation \\
\hline$x$ & Discounts for passengers who move from crowded areas to noncrowded areas \\
\hline$\lambda$ & Passengers' choice; move-1; not move-0 \\
\hline$\theta$ & The probability of moved passengers to swipe the card \\
\hline$W$ & The utility of passengers who choose to move \\
\hline$C$ & The original travel fare \\
\hline$\mu$ & Passenger's perceived coefficient of discount \\
\hline$F$ & The physical energy consumption of passengers to complete the movement \\
\hline$d$ & The average comfort level reduction of passengers in crowded areas \\
\hline$\rho$ & The capacity reduction of the metro station caused by the queue length disequilibrium \\
\hline$U_{A}$ & The utility of the metro passenger \\
\hline$E_{A}$ & The payoff of the metro passenger \\
\hline$\varepsilon_{A}$ & The disturbance of the passenger's utility \\
\hline$U_{B}$ & The utility of the metro company \\
\hline$E_{B}$ & The payoff of the metro company \\
\hline$\varepsilon_{B}$ & The disturbance of the utility of the metro company \\
\hline
\end{tabular}

TABLE 2: Payoffs of the metro passenger and company.

\begin{tabular}{lcc}
\hline \multirow{2}{*}{ Passenger $(A)$} & \multicolumn{2}{c}{ Company $(B)$} \\
& Swipe the card & Not to swipe the card \\
\hline Move & $(W,-x C)$ & $(-F, 0)$ \\
Not to move & $(-d,-\rho)$ & $(-d,-\rho)$ \\
\hline
\end{tabular}

$$
\begin{aligned}
& U_{A}=E_{A}+\varepsilon_{A}, \\
& U_{B}=E_{B}+\varepsilon_{A}, \\
& E_{A}=\lambda(\theta \mu x C+d-F)-d, \\
& E_{B}=\lambda(\rho-\theta x C)-\rho .
\end{aligned}
$$

For the payoff $E_{A}$ of the passenger,

(i) If $x>F-d / \theta \mu C$, the payoff of a passenger can get maximum when $\lambda=1$

(ii) If $x=F-d / \theta \mu C$, the payoff of a passenger is always equal to $-\mathrm{d}$ when $\lambda$ is at any value

(iii) If $x<F-d / \theta \mu C$, the payoff of a passenger can get maximum when $\lambda=0$

(iv) For the payoff $E_{B}$ of the company,

(v) If $x<\rho / \theta C$, the payoff of the company can get maximum when $\lambda=1$

(vi) If $x=\rho / \theta C$, the payoff of the company is always equal to $-\rho$ when $\lambda$ is at any value

(vii) If $x>\rho / \theta C$, the payoff of the company can get maximum when $\lambda=0$

For part passengers, they are supposed to make the decision to move, which is $\lambda=1$. In order to incentivize them to do that, the discount should not be larger than $F-d / \theta \mu C$. To enlarge metro company's benefit, the discount should be smaller than $\rho / \theta C$. Overall, when $F-d / \theta \mu C<x<\rho / \theta C$ and $\lambda=1$, the payoff of metro passengers and the company can both get the maximum.

When $U_{A}^{\lambda=1}>U_{A}^{\lambda=0}$, the passenger will choose to move. Otherwise, he/she will choose not to move. Therefore, the binomial logit model is needed to obtain the probability of the passengers' choice to move:

$$
\begin{aligned}
& P(1)=P\left(U_{A}^{\lambda=1}>U_{A}^{\lambda=0}\right)=\frac{1}{1+e^{-\Delta E_{A}}}, \\
& \Delta E_{A}=\theta \mu x C+d-F .
\end{aligned}
$$

According to the mathematical relationship between the payoff function and the probability of the passengers' choice to move, equation (3) can be transferred into the following equation:

$$
\operatorname{In}\left(\frac{P}{1-\mathrm{P}}\right)=\Delta E_{A}
$$

As there are preferences among every single passenger, differences in personal characteristics and trip characteristics will influence the choice of individuals, and the sensitivity of individuals is varied [46]. Only the discount $x$ can be adjusted by the metro company, while other parameters, such as $\mu, C, d$, and $F$, are all related to the personal characteristics and trip characteristics of passengers. Therefore, it is necessary to conduct a questionnaire survey to calibrate relevant parameters determined by passengers' characteristics and trip characteristics to complete the prediction of passengers' willingness to move.

\subsection{Questionnaire Survey}

2.3.1. Site and Time Selection. According to Gan's classification of metro station types [47], the selected survey sites include university influenced station (SEU Jiulonghu Campus Station, Metro Line 3), employment-oriented station (Andemen Station, Metro Line 10 and 1; Daxinggong Station, Metro Line 2 and 3), residential-oriented station (Wudingmen Station, Metro Line 3), and central business departments that contain shopping and entertainment facilities (Xinjiekou Station, Line 1 and 2; Baijiahu Station, Line 1). These locations are pointed out in Figure 2. Different survey times are selected for different types of metro stations to ensure that different types of passengers are surveyed at an appropriate time. The survey arrangement is shown in Table 3. 


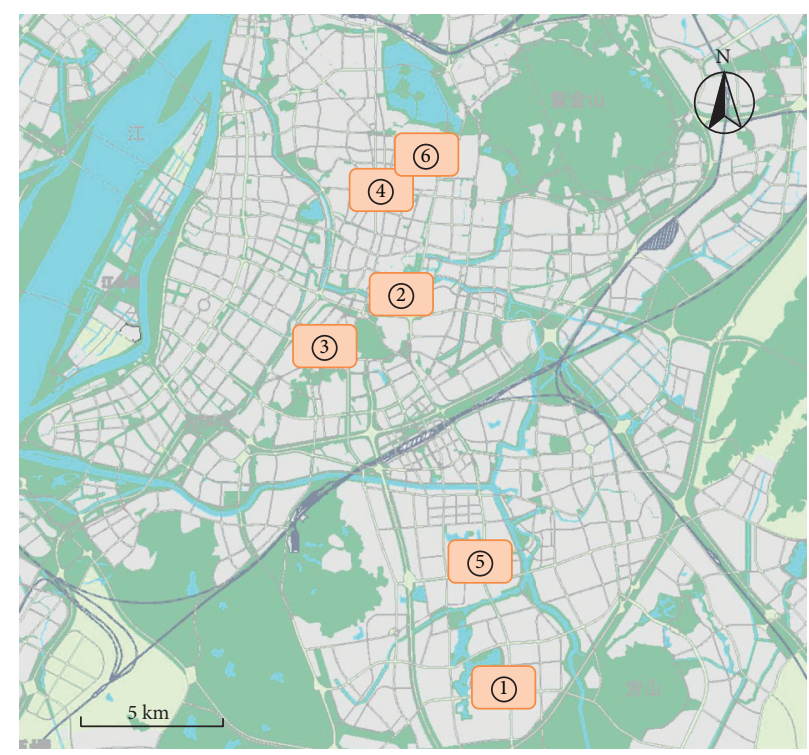

FIgURE 2: Locations of survey sites.

TABLE 3: Timetable of each survey site.

\begin{tabular}{lccc}
\hline Site ID & Metro station & Time & Main respondents \\
\hline (1) & SEU Jiulonghu campus & Week days & Commuters \\
$(2)$ & Wudingmen & Week days & Commuters \\
(3) & Andemen & Week days & Commuters \\
$(4)$ & Xinjiekou & Weekends/holidays & Entertainment travellers \\
(5) & Baijiahu & Weekends/holidays & Entertainment travellers \\
(6) & Daxinggong & Week days & Commuters \\
\hline
\end{tabular}

2.3.2. Respondent Observations. The questionnaire survey was conducted in April and May 2019 by six investigators who are very familiar with the aims of the research and the contents of the questionnaire. In total, 347 questionnaires were collected. 337 questionnaires were valid, accounting for $97 \%$. To maintain the accuracy of the estimations and proper solutions, ensure representativeness, and use multiple observed indicator variables to define latent variables, and a sample size larger than 100 is recommended when maximum likelihood estimation is used [48]. Therefore, a sample size of 337 is adequate for the analysis. The questionnaire collected traveller's personal characteristics (including gender, age, occupation, income, and metro travel frequency) and trip characteristics (including travel fare, travel with luggage or not, travel along or not, travel purpose, travel time, and travel date). Some of the personal trip characteristics of respondents are shown in Table 4. It can be found that respondents are mainly young and middle-aged, and their travel distances are mainly short and medium.

In the questionnaire, passengers' willingness to move from crowded areas to noncrowded areas under the influence of different discount levels was recorded using numbers $0-10$ ( 0 is completely unwilling, 10 is completely willing, and level of willingness increases successively). Its distribution is shown in Figure 3. It can be found that when the discount increases, the passengers are more willing to move.
TABle 4: Sample distribution.

\begin{tabular}{lccc}
\hline Income (RMB) & \multicolumn{3}{c}{ Age } \\
\hline$\leq 50,000$ & $42.90 \%$ & $<20$ & $1.16 \%$ \\
$50,000-100,000$ & $23.19 \%$ & $20-30$ & $37.86 \%$ \\
$100,000-200,000$ & $25.80 \%$ & $30-40$ & $41.04 \%$ \\
$200,000-300,000$ & $7.24 \%$ & $40-50$ & $13.58 \%$ \\
$\geq 300,000$ & $0.87 \%$ & $\geq 50$ & $6.36 \%$ \\
\hline Transit frequency (times/week) & \multicolumn{3}{c}{ Travel fee (RMB) } \\
\hline $0-2$ & $17.29 \%$ & $\leq 3$ & $35.16 \%$ \\
$3-5$ & $26.22 \%$ & 4 & $27.67 \%$ \\
$6-10$ & $25.36 \%$ & 5 & $21.33 \%$ \\
$11-15$ & $23.05 \%$ & 6 & $10.95 \%$ \\
$\geq 16$ & $8.07 \%$ & $\geq 7$ & $4.90 \%$ \\
\hline
\end{tabular}

Combining the personal characteristics and trip characteristics of passengers, the relationship between the discount and the passengers' level of willingness to move was explored by regression analysis.

\section{Results}

3.1. Regression Model. According to the above utility analysis, parameters in equation (4) are related to the characteristics of individual passenger and their trip. Then, introduce two variables $\alpha_{0}$ and $\alpha_{1}$ : 


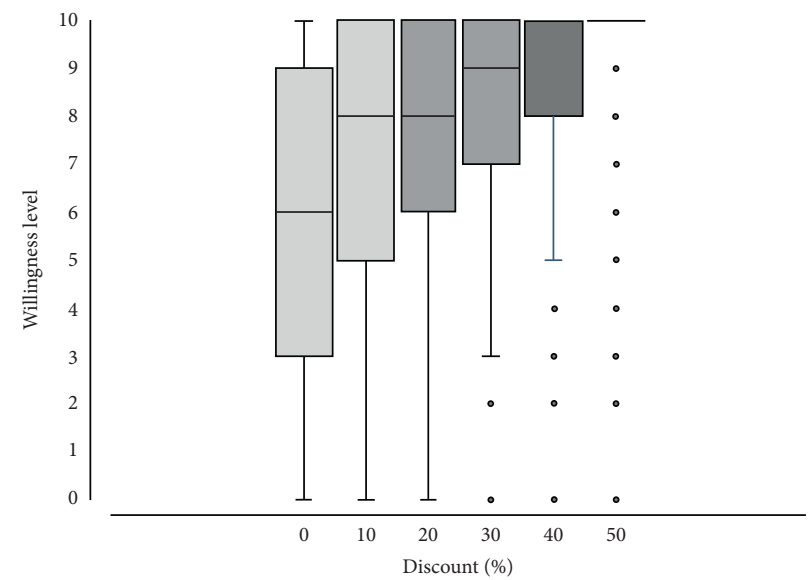

FiguRE 3: Box plots of passengers' willingness level under different discounts.

$$
\begin{aligned}
& \alpha_{0}=d-F, \\
& \alpha_{1}=\theta \mu .
\end{aligned}
$$

Then,

$$
\Delta E_{A}=\alpha_{1} x C+\alpha_{0}
$$

where $\alpha_{0}$ and $\alpha_{1}$ are influenced by passengers' personal and trip characteristics. So, we can assume that

$$
\begin{aligned}
& \alpha_{0}=\beta_{00}+\beta_{01} x_{1}+\beta_{02} x_{2}+\cdots+\beta_{0 n} x_{n}+\varepsilon_{0}, \\
& \alpha_{1}=\beta_{10}+\beta_{11} x_{1}+\beta_{12} x_{2}+\cdots+\beta_{1 m} x_{m}+\varepsilon_{1}, \\
& y=\operatorname{In}\left(\frac{P}{1-P}\right),
\end{aligned}
$$

where $\beta_{i j}(i=0$ and $1 ; j=0,1,2, \ldots)$ is the coefficient of each variable, and $x_{i}(i=1,2,3, \ldots)$ are introduced in Table 5.

Therefore, the regression model with interaction terms can be used to describe the interactions among these variables [49]:

$$
\begin{aligned}
y= & \beta_{00}+\beta_{01} x_{1}+\beta_{02} x_{2}+\cdots+\beta_{0 n} x_{0 n}+\beta_{10} x_{d}+\beta_{11} x_{1} x_{d} \\
& +\beta_{12} x_{2} x_{d}+\cdots+\beta_{1 m} x_{m} x_{d}+\varepsilon,
\end{aligned}
$$

where $y$ is the natural logarithm of the ratio of the willingness level to unwillingness level, $x_{d}$ is the discount, which ranges from 0 to $50 \%$, and $x_{i}(i=1,2,3,4, \ldots)$ represents the variable related to personal characteristics and trip characteristics. Variables are explained in detail in Table 5. None of the variables in our model correlate strongly enough with each other.

In Table 5, items with the symbol $\mathbf{\Delta}$ are binary variables, while those with the symbol $\boldsymbol{\nabla}$ are nominal scale variables. $n-1$ dummy variables must be created to represent all $n$ levels of the nominal scale variable in the regression model. The travel purpose and the passengers' occupation were both divided into 4 levels and are shown in Table 5, and 3 dummy variables were used to represent the travel purpose or the passenger's occupation jointly $[50,51]$. Items with the symbol $\bullet$ are ordered scale variables. The value of each ordered scale variable is indicated in Table 5, which is the value of the ordered variable set equivalent to the actual situation. In our survey, the luggage which cannot be carried on the hands or back all the travel time is defined as the large luggage. These large will make passengers' movement more difficult.

Before the regression calculation, all explanatory variables are standardized to facilitate the comparison of the influence degree of each variable in the regression results on the response variable [52]. Through regression analysis, the interactions between each explanatory variable and response variable are shown in Table 6.

As shown in Table 6, many explanatory variables are not significant in the model with all interaction terms. Compared with the regression model without interaction terms, it is found that the reduction of interaction terms does not have a great impact on the adjusted $R$-squared of the model, and the significance of some variables, such as gender, age, and travel with luggage, is even increased. This shows that, in the utility function of game theory, the influence of each explanatory variable on the response variable needs to be adjusted. After adjustment on explanatory variables, the final model is shown in the last column of Table 6. The adjusted $R$-square is 0.4192 , which is the highest among the three models. This indicates that the model can explain the relationship between the explanatory variable and the response variable within a reasonable range. Some variables are not significant, such as travel with companion and the interaction term of travel fee, but they are still retained because the deletion of them will reduce the adjusted $R$ square of the model, and they are important characteristics of passengers.

\subsection{Results Analysis and Discussion}

3.2.1. Results Analysis. The value of response variable In $(P / 1-P)$ is monotonically increasing with the increase of $P$. Therefore, the variables with a negative coefficient in the final model (i.e., occupation and travel purpose) have 
TABLE 5: Explanation of variables of the regression model.

\begin{tabular}{|c|c|c|}
\hline Variables & & Explanation \\
\hline Gender $\boldsymbol{\Delta}$ & $x_{1}$ & Male- 0 ; female- 1 \\
\hline Date $\boldsymbol{\Delta}$ & $x_{2}$ & Weekday-0; weekend-1 \\
\hline Time & $x_{3}$ & Off-peak hours-0; peak hours-1 \\
\hline Travel with companion $\Delta$ & $x_{4}$ & A respondent travelled with companions or not; no-0; yes-1 \\
\hline Travel with luggage $\boldsymbol{\Delta}$ & $x_{5}$ & A respondent travelled with large luggage or not; no- 0 ; yes-1 \\
\hline Travel fee & $x_{6}$ & The cost of this trip of a respondent; $x_{6}=2,3,4, \ldots, 8$ \\
\hline Travel purpose $\boldsymbol{\nabla}$ & & The travel purpose of a respondent \\
\hline Work/school & $x_{71}$ & No- 0 ; yes- 1 \\
\hline Home & $x_{72}$ & No-0; yes-1 \\
\hline Entertainment & $x_{73}$ & No-0; yes-1 \\
\hline Frequency & $x_{8}$ & The travel frequency by the metro of a respondent is high or low; $x_{8}=1,2,3,4, \ldots, 7$ \\
\hline Occupation $\boldsymbol{\nabla}$ & & A respondent has a regular income \\
\hline Student & $x_{91}$ & No-0; yes-1 \\
\hline Retired person & $x_{92}$ & No-0; yes-1 \\
\hline Nine-to-fiver & $x_{93}$ & No-0; yes-1 \\
\hline Age & $x_{10}$ & The age level of respondents; $x_{10}=1,2,3,4, \ldots, 8$ \\
\hline Income & $x_{11}$ & The income level of respondents; $x_{11}=1,2,3,4, \ldots, 8$ \\
\hline Weather $\boldsymbol{\Delta}$ & $x_{12}$ & Rainy-0; not rainy-1 \\
\hline Discount $\bullet$ & $x_{d}$ & Discounts on the travel fee; $x_{d}=0,1,2,3,4$, and 5 \\
\hline
\end{tabular}

TABLe 6: Logistic regression: response variable $\operatorname{In}(P / 1-P)$.

\begin{tabular}{|c|c|c|c|c|}
\hline & Response variable: $\operatorname{In}(P / 1-P)$ & With interactions & Without interactions & Final model \\
\hline \multirow{17}{*}{ Respondent characteristics } & Explanatory variables: & $\beta$ & $\beta$ & $\beta$ \\
\hline & Discount & $4.1484^{* * *}$ & $4.4686^{* * *}$ & $4.7913^{* * *}$ \\
\hline & Gender & $0.5585^{*}$ & $0.5677^{* * *}$ & $0.5359^{* * *}$ \\
\hline & Gender $*$ discount & -0.0212 & & \\
\hline & Age & $3.4793^{* *}$ & $4.0841^{* * *}$ & $3.7670^{* * *}$ \\
\hline & Age $*$ discount & 1.2214 & & \\
\hline & Income & 0.1494 & -0.3412 & \\
\hline & Income $*$ discount & -0.9748 & & \\
\hline & Frequency & $-1.2767^{*}$ & -0.5251 & \\
\hline & Frequency $*$ discount & 1.5059 & & \\
\hline & Occupation & & & \\
\hline & Student & $-1.0072^{*}$ & $-0.7532^{* *}$ & $-0.7489^{* *}$ \\
\hline & Student $*$ discount & 0.5232 & & \\
\hline & Retired person & -0.7349 & $-1.4514^{*}$ & -1.1993 \\
\hline & Retired person $*$ discount & -1.4285 & & \\
\hline & Nine-to-fiver & -0.0331 & 0.0979 & -0.0405 \\
\hline & Nine-to-fiver $*$ discount & 0.2671 & & \\
\hline \multirow{14}{*}{ Trip characteristics } & Weather & -0.0613 & -0.1936 & \\
\hline & Date & $1.5326^{* * *}$ & $1.5287^{* * *}$ & $1.5352^{* * *}$ \\
\hline & Time & $1.0496^{* * *}$ & $1.0414^{* * *}$ & $0.9321^{* * *}$ \\
\hline & Travel with companion & -0.2779 & -0.2784 & -0.3165 \\
\hline & Travel with luggage & -0.5547 & $-0.5520^{*}$ & \\
\hline & Travel fee & 0.1499 & -0.4232 & \\
\hline & Travel fee $*$ discount & -1.1381 & & -1.0240 \\
\hline & Travel purpose & & & \\
\hline & Work/school & $-1.0552^{* *}$ & $-1.0661^{* *}$ & $-1.4188^{* * *}$ \\
\hline & Home & $-0.9868^{* *}$ & $-0.9997^{* *}$ & $-1.3910^{* * *}$ \\
\hline & Entertainment & $-1.1278^{* *}$ & $-1.1382^{* *}$ & $-1.4235^{* * *}$ \\
\hline & $N$ & 2022 & 2022 & 2022 \\
\hline & $R$-squared & 0.4246 & 0.4236 & 0.4229 \\
\hline & Adjusted $R$-squared & 0.4174 & 0.4187 & 0.4192 \\
\hline
\end{tabular}

${ }^{*} p<0.1 .{ }^{* *} p<0.05 .{ }^{* * *} p<0.01$.

negative impacts on the response variable, thus have the same impact on the passenger's willingness, and vice versa. According to the final model, it can be found that the discount level is a significant factor with the largest elasticity on the response variable. This finding suggests that passengers' behaviour can be changed through monetary 


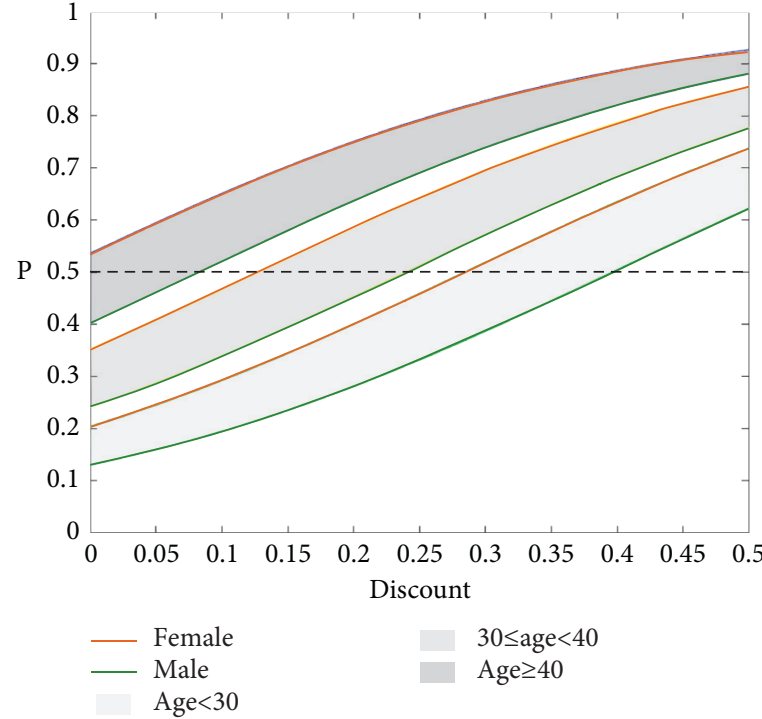

(a)

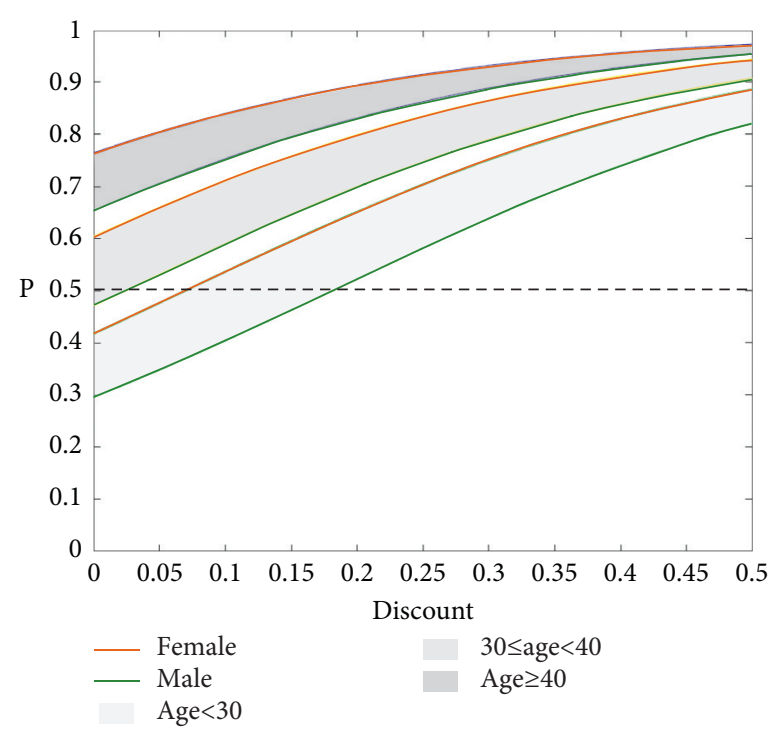

(b)

FIGURE 4: Model prediction of passengers' willingness to move under different discount. (a) Weekday. (b) Weekend.

incentives, and the price can significantly affect the passenger's willingness to move. In addition, the age of passengers and whether the travel is made on a working day also play an important role in the passenger's willingness. Older passengers and weekend travellers are more willing to move.

The results of the model also present some unexpected phenomena. For example, the passenger's income does not have a significant impact on the passenger's willingness to move, and neither the travel fare nor its interaction item (fare * discount) have the significant influence on passengers' willingness, which indicates that passengers' sensitivity to discount has little correlation with the travel cost.

However, it does not mean the more passengers choose to move the merrier. The purpose of this policy is to motivate some of the passengers in the crowded areas to move, not all of them. Therefore, passengers can be classified according to the factors with the largest elasticities to the response variable. The critical values of discount for each category of passengers are different. The proportion of passengers choosing to move can be manipulated through varying the discount so that the distribution of passengers on the platform can get an equilibrium. Numerical analysis is carried out according to the passenger composition of the questionnaire survey data in this paper.

Passengers were divided into three categories according to their age, age $<30,30 \leq$ age $<40$, and age $\geq 40$. Each of them can travel on weekdays or weekends. Figures 4(a) and 4(b) show the estimated level of willingness of passengers in different age groups. Passengers' income and travel frequency were set to the average value of the sample, and their occupations were all set to nine-to-fiver. The travel purpose was commuting for work on weekdays and entertainment on weekends. All other variables were set to 0 . The critical value of the discount can be obtained in Figure 4. The example is to demonstrate how the distribution of passengers on the platform is regulated by discount. Therefore, a simple classification standard is selected to show the adjustment process. In practical applications, it is possible to classify passengers in a more detailed way.

3.2.2. Optimal Discount Level Determination. The critical values of discount for each category of passengers are shown in Table 7. According to the survey data, it is assumed that the composition of passengers in peak hours of a metro station on weekdays is shown in Table 8 .

When $20 \%$ of passengers on the metro station platform need to be motivated to move from crowded areas to specified areas to achieve the equilibrium of passenger distribution in the whole metro system (which takes the congested states both on the platform and in carriage into consideration), a discount of $15 \%$ should be set so that elderly passengers and middle-aged female passengers would like to move, which accounts for $22 \%$ of the total number of passengers, basically meeting the target. If combined with real-time discount control, more accurate regulation can be achieved.

The above research results show that the monetary incentive policy can be modified for the distribution of boarding passengers on the metro station platform to be equilibrated. However, will the metro company benefit more by carrying out this policy? According to the above analysis, it can be found that the utility of the metro company will remain increasing or unchanged when the discount level $x \leq \rho / \theta C$. $\theta$ is the probability of moved passengers to swipe the card, which was calibrated as $65.7 \%$ according to the questionnaire results. $\rho$ is the capacity reduction of the metro station caused by the queue length disequilibrium, which can be measured by the reduction on the total travel fare of passengers. Hence, $\rho=\rho^{\prime} \cdot C$, where $\rho$ is the reduction percentage of passenger volume that a metro station can contain due to the queue length disequilibrium. The 
TABLE 7: Critical values of discount.

\begin{tabular}{ccccc}
\hline $\begin{array}{c}\text { Critical discount } \\
\text { value }\end{array}$ & Age $<30(\%)$ & $30 \leq$ age $<40(\%)$ & Age $\geq 40$ \\
\hline \multirow{2}{*}{ Weekday } & Male & 40 & 24 & $8 \%$ \\
& Female & 28 & 13 & 0 \\
\hline \multirow{2}{*}{ Weekend } & Male & 18 & 3 & 0 \\
& Female & 7 & 0 & 0 \\
\hline
\end{tabular}

TABLE 8: Composition of passengers.

\begin{tabular}{lccc}
\hline Age & Percentage $(\%)$ & Gender & Percentage (\%) \\
\hline$<30$ & 62 & Male & 62 \\
$30 \leq$ age $<40$ & 26 & Female & 38 \\
$\geq 40$ & 12 & & \\
\hline
\end{tabular}

condition $x \leq \rho / \theta C$ can be written as $x \leq \rho^{\prime} / \theta$. In the numerical example above, it can be easily found that $\rho^{\prime}>20 \%$, so the discount level of $15 \%$ can make the metro company more profitable.

\section{Conclusions}

This study applied the monetary incentive policy to metro passengers on the platform to regulate boarding passenger distribution on the metro station platform, which aims to achieve the equilibrium of passenger distribution in the metro system. Upon the utility analysis of passengers and metro companies caused by the monetary incentive policy, the interactions between passengers' willingness to move from crowded areas to noncrowded/specified areas and different discount levels are explored by the logit model. Using the questionnaire data collected from metro passengers in Nanjing, China, passengers' preferences were analyzed according to the regression model. The regression results showed that female, elder, and weekend travellers are more sensitive to the discount. Most passengers aged over 40 were willing to move at a $10 \%$ discount, while passengers aged under 30 need a discount of up to $40 \%$ to motivate them to move. A $30 \%$ discount works on most female passengers. The metro company can adjust the discount level to motivate a specific proportion of passengers to achieve the regulation of passenger distribution. And, it has been proved that if the average discount is smaller than the reduction percentage of passenger volume that a metro station can contain due to the queue length disequilibrium, both passengers and the metro company will benefit.

However, there are still some limitations of this policy and this study. As for the policy, the composition of passengers on the metro station platform is hard to know at present because passengers' location on the platform and personal characteristics cannot be recorded. With the development of electronic tickets on the smartphone, the personal characteristics can be recorded in the APPs for paying (such as Alipay and WeChat), and passengers' location is easy to distinguish with the smartphone Bluetooth or other signalling. As for this study, the variables in the utility function are defined in the generalization. More detailed formulation and calibration of these variables, such as the passenger distribution, should be completed in future work. And, more research is needed to illustrate the safety issues of this policy.

\section{Data Availability}

The data used to support the findings of this study are available from the corresponding author upon request.

\section{Conflicts of Interest}

The authors declare that they have no conflicts of interest.

\section{Acknowledgments}

This work was financially supported by the National Key R\&D Program of China (2018YFB1600900), National Key R\&D Program of China (2018YFE0120100), Scientific Research Foundation of Graduate School of Southeast University (YBPY2040), and National Demonstration Center for Experimental Road and Traffic Engineering Education (Southeast University).

\section{References}

[1] M. A. A. Boon, O. J. Boxma, O. Kella, and M. Miyazawa, "Queue-length balance equations in multiclass multiserver queues and their generalizations," Queueing Systems, vol. 86, no. 3-4, pp. 277-299, 2017.

[2] A. Larsson, E. Ranudd, E. Ronchi, A. Hunt, and S. Gwynne, "The impact of crowd composition on egress performance," Fire Safety Journal, vol. 120, Article ID 103040, 2021.

[3] N. Krstanoski, "Modelling passenger distribution on metro station platform," International Journal of Traffic and Transportation Engineering, vol. 4, no. 4, pp. 456-465, 2014.

[4] S. C. Wirasinghe and D. Szplett, "An investigation of passenger interchange and train standing time at LRT stations: (ii) estimation of standing time," Journal of Advanced Transportation, vol. 18, no. 1, pp. 13-24, 1984.

[5] Z. Cao, S. Jiang, J. Zhang, and H. Guo, "A unified framework for vehicle rerouting and traffic light control to reduce traffic congestion," IEEE Transactions on Intelligent Transportation Systems, vol. 18, no. 7, pp. 1958-1973, 2017.

[6] J. Chen and C. L. Yuan, "Urban oversaturated traffic network control based on preference multi-objective compatible optimization control," Advanced Materials Research, vol. 47, pp. 13-16, 2011.

[7] X. Gu, M. Abdel-Aty, Q. Xiang, Q. Cai, and J. Yuan, "Utilizing UAV video data for in-depth analysis of drivers' crash risk at interchange merging areas," Accident Analysis and Prevention, vol. 123, pp. 159-169, 2019.

[8] P. Lertworawanich, M. Kuwahara, and M. Miska, "A new multiobjective signal optimization for oversaturated networks," IEEE Transactions on Intelligent Transportation Systems, vol. 12, pp. 967-976, 2011.

[9] X. Liu, S. Tang, F. Zhu, and Z. Chen, "Urban area oversaturated traffic signal optimization control based on MFD," Acta Automatica Sinica, vol. 43, pp. 1220-1233, 2017.

[10] K. Jang, H. Kim, and I. G. Jang, "Traffic signal optimization for oversaturated urban networks: queue growth equalization," IEEE Transactions on Intelligent Transportation Systems, vol. 16, no. 4, pp. 2121-2128, 2015. 
[11] R. Hassin and M. Haviv, To Queue or Not to Queue: Equilibrium Behavior in Queueing Systems, Springer, Boston, MA, USA, 2003.

[12] C. Sun, L. Cheng, S. Zhu, F. Han, and Z. Chu, "Multi-criteria user equilibrium model considering travel time, travel time reliability and distance," Transportation Research Part D-transport and Environment, vol. 66, pp. 3-12, 2017.

[13] G. Giambene, Queuing Theory and Telecommunications, Springer, Berlin, Germany, 2014.

[14] S. C. Graves, "The application of queueing theory to continuous perishable inventory systems," Management Science, vol. 28 , no. 4, pp. 400-406, 1982.

[15] D. Gross, J. F. Shortle, J. M. Thompson, and C. M. Harris, "Fundamentals of queueing theory," Technometrics, vol. 41, pp. 76-77, 1999.

[16] P. Van Mieghem, "The asymptotic behavior of queueing systems: large deviations theory and dominant pole approximation," Queueing Systems, vol. 23, no. 1-4, pp. 27-55, 1996.

[17] H. Liu, H. Yin, Y. Zhou, and M. Li, "Cooperative hypercube queuing model for emergency service systems," Journal of Advanced Transportation, vol. 2021, Article ID 6653573, 2021.

[18] V. Bhaskar and P. Lallement, "Queuing network model of uniformly distributed arrivals in a distributed supply chain using subcontracting," Decision Support Systems, vol. 51, no. 1, pp. 65-76, 2011.

[19] F. Spies, "Modeling of optimal load balancing strategy using queueing theory," Microprocessing and Microprogramming, vol. 41, no. 8-9, pp. 555-570, 1996.

[20] C. Osorio and M. Bierlaire, "An analytic finite capacity queueing network model capturing the propagation of congestion and blocking," European Journal of Operational Research, vol. 196, no. 3, pp. 996-1007, 2009.

[21] Y. Wang and Z. Liu, "Equilibrium and optimization in a double-ended queueing system with dynamic control," Journal of Advanced Transportation, vol. 2019, Article ID 6538265, 2019.

[22] S. Afandizadeh Zargari and F. Safari, "Using clustering methods in multinomial logit model for departure time choice," Journal of Advanced Transportation, vol. 2020, Article ID 7382569, 2020.

[23] P. Naor, "The regulation of queue size by levying tolls," Econometrica, vol. 37, no. 1, pp. 15-24, 1969.

[24] N. M. Edelson and D. K. Hilderbrand, "Congestion tolls for Poisson queuing processes," Econometrica, vol. 43, no. 1, pp. 81-92, 1975.

[25] Y. Liu, Z. Liu, and R. Jia, "DeepPF: a deep learning based architecture for metro passenger flow prediction," Transportation Research Part C: Emerging Technologies, vol. 101, pp. 18-34, 2019.

[26] A. Manou, A. Economou, and F. Karaesmen, "Strategic customers in a transportation station: when is it optimal to wait?” Operations Research, vol. 62, no. 4, pp. 910-925, 2014.

[27] O. Bountali and A. Economou, "Equilibrium threshold joining strategies in partially observable batch service queueing systems," Annals of Operations Research, vol. 277, no. 2, pp. 231-253, 2019.

[28] A. Manou, P. G. Canbolat, and F. Karaesmen, "Pricing in a transportation station with strategic customers," Production and Operations Management, vol. 26, no. 9, pp. 1632-1645, 2017.

[29] F. Wang, J. Wang, and Z. G. Zhang, "Strategic behavior and social optimization in a double-ended queue with gated policy," Computers and Industrial Engineering, vol. 114, pp. 264-273, 2017.

[30] P. Liu, J. Lv, T. Jiang, and X. Chai, "Equilibrium joining strategies of delay-sensitive customers in a queueing system with service quality feedback," Discrete Dynamics in Nature and Society, vol. 2020, Article ID 5906407, 2020.

[31] R. B. Dial, "Network-optimized road pricing: part I: a parable and a model," Operations Research, vol. 47, no. 1, pp. 54-64, 1999.

[32] G. Santos and L. Rojey, "Distributional impacts of road pricing: the truth behind the myth," Transportation, vol. 31, no. 1, pp. 21-42, 2004.

[33] C.-P. Heller, J. Johnen, and S. Schmitz, "Congestion pricing: a mechanism design approach," Journal of Transport Economics and Policy, vol. 53, pp. 74-98, 2019.

[34] F. H. Knight, "Some fallacies in the interpretation of social cost," Quarterly Journal of Economics, vol. 38, no. 4, pp. 582-606, 1924.

[35] D. Z. Rich, The Economics of Welfare, Routledge, New York, NY, USA, 1924.

[36] M. Börjesson, J. Eliasson, M. B. Hugosson, and K. BrundellFreij, "The Stockholm congestion charges- 5 years on. Effects, acceptability and lessons learnt," Transport Policy, vol. 20, pp. 1-12, 2012.

[37] A. L. Broaddus, The Adaptable City: The Use of Transit Investment and Congestion Pricing to Influence Travel and Location Decisions in London, UC Berkeley, Berkeley, CA, USA, 2015.

[38] T. Chronopoulos, "Congestion pricing: the political viability of a neoliberal spatial mobility proposal in London, Stockholm, and New York City," Urban Research and Practice, vol. 5, no. 2, pp. 187-208, 2012.

[39] J. Eliasson and L.-G. Mattsson, "Equity effects of congestion pricing," Transportation Research Part A: Policy and Practice, vol. 40, no. 7, pp. 602-620, 2006.

[40] L. Cheng, X. Chen, S. Yang, Z. Cao, J. De Vos, and F. Witlox, "Active travel for active ageing in China: the role of built environment," Journal of Transport Geography, vol. 76, pp. 142-152, 2019.

[41] U. S. Kandolath, "Regulating travel demand for sustainable transport: road pricing versus incentive schemes," Springer Transactions in Civil and Environmental Engineering, pp. 259-264, 2019.

[42] R. B. Noland, M. A. Quddus, and W. Y. Ochieng, "The effect of the London congestion charge on road casualties: an intervention analysis," Transportation, vol. 35, pp. 73-91, 2008.

[43] R. Edelstein and M. Srkal, "Congestion pricing," ITE Journal, vol. 61, pp. 15-18, 1991.

[44] R. Lindsney and E. Verhoef, "Traffic congestion and congestion pricing," in Handbook of Transport Systems and Traffic Control, K. J. Button and D. A. Hensher, Eds., vol. 3, pp. 77-105, Emerald Group Publishing Limited, Bingley, England, 2001.

[45] J. C. Redmon, YOLO: Real-Time Object Detection, 2018, https://pjreddie.com/darknet/yolo/.

[46] C. Camerer, "Behavioral game theory: experiments in strategic interaction," Cuadernos De Economía, vol. 23, pp. 229-236, 2004.

[47] Z. Gan, M. Yang, T. Feng, and H. J. P. Timmermans, "Understanding urban mobility patterns from a spatiotemporal perspective: daily ridership profiles of metro stations," Transportation, pp. 1-22, 2018. 
[48] A. Boomsma, "Nonconvergence, improper solutions, and starting values in LISREL maximum likelihood estimation," Psychometrika, vol. 50, no. 2, pp. 229-242, 1985.

[49] Y. Fan, A. Guthrie, and D. Levinson, "Waiting time perceptions at transit stops and stations: effects of basic amenities, gender, and security," Transportation Research Part A: Policy and Practice, vol. 88, pp. 251-264, 2016.

[50] Y. Fan, Y. Jin, L. Gao, Y. Ji, and X. Ma, "Do Monetary incentive measure effects on user's illegal parking behavior of station-free shared bike? a case study of Nanjing, China," in Proceedings of the 98th Annual Meeting of the Transportation Research Board, Washington, DC, USA, January 2019.

[51] Y. Ji, L. Gao, Y. Fan, C. Zhang, and R. Zhang, "Waiting time perceptions at bus and metro stations in Nanjing, China: the importance of station amenities, trip contexts, and passenger characteristics," Transportation Letters, vol. 11, pp. 1-7, 2019.

[52] S. P. Washington, M. G. Karlaftis, and F. Mannering, Statistical and Econometric Methods for Transportation Data Analysis, Taylor \& Francis Group, New York, NY, USA, 2003. 